\title{
Efficacy of Endoscopic Endonasal Common Canaliculorhinostomy for Chronic Dacryocystitis with Small Lacrimal Sac in the Treatment of Failed Patients After EE-DCR
}

Sha Li

Hankou Eye Hospital of Wuhan Aier

Yong Zhang (D619378970@qq.com )

Hankou Eye Hospital of Wuhan Aier

\section{Research Article}

Keywords: Endoscopic endonasal, common canaliculorhinostomy, Endoscopic endonasal dacryocystorhinostomy, Failed surgery, Efficacy comparison

Posted Date: February 14th, 2022

DOI: https://doi.org/10.21203/rs.3.rs-1305442/v1

License: (c) (1) This work is licensed under a Creative Commons Attribution 4.0 International License. Read Full License 


\section{Abstract}

Background: Over the past 10 years, endoscopic endonasal dacryocystorhinostomy (EE-DCR囚has a trend to gradually become the mainstream method for the treatment of nasolacrimal duct obstructive diseases , but the failure of EE-DCR is not rare in clinical treatment. Therefore, the study will explore the efficacy of treating patients with EE-DCR failure by endoscopic endonasal common canaliculorhinostomy (EE-CAR), in order to improve the success rate of reoperation in patients with EE-DCR failure.

Method: Prospective non-randomized controlled study. Patients with EE-DCR failure caused by lacrimal sac nasal mucosal ostium atresia from April 2018 to January 2021 in Hankou Aier Eye Hospital were enrolled. They were divided into two groups according to the principle of voluntariness before surgery. Group A: underwent EE-CAR. Group B: underwent Endoscopic Endonasal Ostial Openning (EE-OO). The postoperative efficacy and complications of the two groups was compared.

Results: 44 patients (48 eyes) were included in the comparative analysis, including 26 eyes in group A and 22 eyes in group B. Followed up at 6 months postoperative, the ostium of 22 eyes in group A remained open and the symptoms of tear overflow disappeared. The success rate of surgery was $84.62 \%$ $(22 / 26)$, and $54.55 \%(12 / 22)$ in group B. There was significant difference between the two groups (P区 $0.05)$.

Conclusions: EE-CAR is better than conventional ostium opening in the treatment of patients with small lacrimal sac remnant after EE-DCR due to ostium atresia.

\section{Background}

For lacrimal duct obstructive diseases, especially chronic dacryocystitis, surgery is recognized as the most effective treatment [1-2]. The existing surgical methods include lacrimal intubation, YAG laser, external dacryocystorhinostomy (Ex-DCR) and EE-DCR [3-4]. For more than 100 years, Ex-DCR has been regarded as the "gold standard" for the treatment of chronic dacryocystitis, but it can't meet people's growing medical needs due to the shortcomings of facial skin scar, large trauma, affecting the function of "tear pump" and unable to deal with nasal complications at the same time [5-7]. Over the past 10 years, with the continuous improvement of endoscopic imaging system, ENT micro power system and other medical equipment, EE-DCR is highly recommended in clinic because of its incomparable advantages of Ex-DCR, such as no facial skin incision, minimally invasive and does not affect the function of "tear pump", simultaneous treatment of nasal complications, et al. However, so far, the efficacy of EE-DCR has been reported differently, and its losers are not rare [8-10]. Research has found that the main reason for the failure of EE-DCR is the atresia of rhinostomy ostium, and the residual lacrimal sac is very small [1113]. When ostium closure occurs, clinical treatment methods are different. Some studies suggest that lacrimal probe can be used to probing the closed ostium, or YAG laser can be used to open the ostium and insert artificial lacrimal stent at the same time, but the above treatment effects are not ideal [14-15]. It is also reported that rhinostomy ostium incision can be performed to reopen the closed ostium and its 
curative effect is not very impressive [16]. The study found that in the failures after EE-DCR due to rhinostomy ostium atresia, the residual lacrimal sac of most patients is very small, which adds a considerable obstacle to the success of EE-DCR again [17-18]. The key to the success of EE-DCR lies in the "valve valve anastomosis" between the lacrimal sac valve and the nasal mucosa valve, so as to improve the healing and epithelization of the ostium. We envisage that based on EE-DCR, the ostium should be opened as completely as possible to the common canaliculus when cutting the residual lacrimal sac, here, it's called endoscopic endonasal common canaliculorhinostomy(EE-CAR). Therefore, this project intends to explore the efficacy of EE-CAR in the treatment of patients with failure and residual small lacrimal sac after EE-DCR, and compare it with endoscopic endonasal ostial opening (EE-OO) to evaluate the clinical value of EE-CAR, so as to improve the success rate of reoperation in patients with failure of EE-DCR and provide reference basis for ophthalmic clinical work.

\section{Materials And Methods}

This prospective randomized controlled study was conducted in Hankou Hospital of Wuhan Aier Eye Hospital from April 2018 to January 2021. The study adhered to the tenets of the Declaration of Helsinki and was approved by ethics committee of Hankou Eye Hospital of Wuhan Aier (approval No.:HKAIER2018IRB-002-01). All patients were informed in detail before surgery and signed the informed consent for this study and surgery. Follow-up after surgery regular.

The inclusion criteria of this study were that the patient had received EE-DCR for chronic dacryocystitis. After 12 months of treatment, it was found that the ostium between the original nasal cavity and the lacrimal sac flap mucosa healed and closed, and there were: (1) the patient had tears and a little pus; (2) lacrimal passage flushing examination: inject flushing fluid into the needle from one lacrimal punctum, and the flushing fluid returns to the other lacrimal punctum; (3) CT angiography of lacrimal sac showed that the residual lacrimal sac was small, showing that the horizontal diameter of lacrimal sac was $\leq 2 \mathrm{~mm}$, the sagittal diameter was $\leq 4 \mathrm{~mm}$, and the vertical diameter was $\leq 8 \mathrm{~mm}[11,15]$. Exclusion criteria included: (1) trauma of nose, eyelid and orbit; (2) complicated with severe nasal polyps, nasal tumors, severe deviation of nasal septum, hypertrophy of nasal turbinate, nasal radiotherapy and chemotherapy; (3) patients with ocular surface, lacrimal punctum and / or lacrimal canaliculi diseases; (4) suffering from serious blood system diseases; (5) incomplete regular follow-up data or failure to follow the doctor's advice; (6) those who can't tolerate the surgery.

All selected cases were divided into two groups according to the principle of voluntariness. Group A received EE-CAR and group $B$ received EE-OO. We recorded the age, eye type, gender, major complain, course of disease and outcomes. All patients were performed by a single surgeon (YZ).

Surgical technique of experimental group (group A): after anesthesia, the lacrimal probe enters from the lower lacrimal punctum until the mucosa at the closed ostium can be seen under nasal endoscopy and the mucosa moves with the probe. Incision of mucosa at the ostium in the shape of " [ " around the probe. Expand and widen the bone hole to the required size until the common canaliculus is completely 
exposed. Observe and confirm whether the position and size of the bone hole are appropriate under nasal endoscopy (Fig. 1A). After the lacrimal probe enters from the lower lacrimal punctum, push the probe horizontally and further push the inner wall of the lacrimal sac. Incision of lacrimal sac mucosa along the highest part of tissue eminence, expose the lacrimal probe, completely cut off the scar and granulation tissue at the original ostium, retain at least $2 \sim 3 \mathrm{~mm}$ normal mucosal tissue around the opening of common canaliculus, trim the tissue around the common canaliculus to make the opening of common canaliculus flush with its surrounding tissue, until the opening of common canaliculus is completely exposed to the nasal cavity. For those without common canaliculus structure, the openings of the upper and lower lacrimal canaliculi in the lacrimal sac area were directly exposed. The mucosa around the ostium was glued with medical adhesive to fix the position of the mucosal flap and make it difficult to move. Tobramycin dexamethasone eye ointment was injected into the upper and lower lacrimal punctums respectively, Avitene Microfibrillar Collagen Hemostat Flour (C. R. Bard, Inc, United States) was mixed with normal saline, and the reconciled Avitene Microfibrillar Collagen Hemostat Flour was used to fill the ostium and nasal cavity (Fig. 1B),

Surgical technique of control group (group B): after anesthesia, the lacrimal probe enters from the lower lacrimal punctum until the mucosa at the original ostium moves with the probe under nasal endoscopy, and a "+" incision is made at the top of the mucosa. The bone biting forceps began to bite off the mucosa at the ostium along the center of the " + " incision and remove the scar tissue at the center. Until the lacrimal probe can smoothly enter the ostium from the lacrimal punctum, take out the lacrimal probe, continue to expand the aperture of the ostium, and make an ostium of about $5-6 \mathrm{~mm}$. Tobramycin dexamethasone eye ointment was injected into the upper and lower lacrimal punctums respectively. Avitene Microfibrillar Collagen Hemostat Flour was mixed with normal saline, and the reconciled Avitene Microfibrillar Collagen Hemostat Flour was used to fill the ostium and nasal cavity.

Postoperative disposition: the patients were given levofloxacin eye drops for 1 month, $0.02 \%$ fluoromilone eye drops for 2 weeks, $1 \%$ tiolozolin hydrochloride nasal spray for 1 months. Pay close attention to the bleeding in nasal cavity and inner canthus postoperative, and follow up to 6 months after surgery. Lacrimal duct irrigation test and nasal endoscopic examination were performed at 2 weeks, 1 month, 3 months and 6 months after surgery. The patency and growth of ostium were observed, and the formation of granulation tissue within $5 \mathrm{~mm}$ around ostium, the formation of scar hyperplasia and postoperative curative effect were recorded.

The successful surgery was defined as the ostium opening , and the patient had no symptoms of tears and pus. Surgical failure was defined as any of the following: (1) the symptoms of epiphora were not significantly relieved; (2) Lacrimal duct flushing is not unobstructed or there is more reflux, and even the reflux is accompanied by secretion and ostium closure.

Statistical analysis were performed with SPSS version 26.0 (SPSS Inc., Chicgo, IL). Chi-Square test, t-test or Mann-Whitney U test was used for comparison of date. Results were considered significant at $P \otimes 0.05$. 


\section{Results}

Excluding the incomplete follow-up data of 3 patients (3 eyes), 44 patients (48 eyes) were included in the comparative analysis, including 26 eyes in group A and 22 eyes in group $B$. There was no significant difference in gender, eye type, age and course of disease between the two groups ( $P \otimes 0.05)$ (Table 1).

During the 6-month follow-up ((Fig. 2A D), there were 4 eyes with complete atresia of ostium in group A, of which 1 eye was caused by excessive granulation tissue aggregation and adhesion, 2 eyes were caused by excessive scar hyperplasia at the ostium, 1 eye was caused by the obstruction of ostium by hyperplastic granulation tissue and scar. The success rate of surgery was $84.62 \%(22 / 26)$. In group B, there were 10 eyes with complete atresia of ostium, of which 3 eyes were caused by excessive granulation tissue aggregation and adhesion; 4 eyes were caused by excessive scar hyperplasia at the ostium site, 3 eyes were caused by the obstruction of ostium by excessive hyperplasia of granulation tissue and scar, and the success rate of surgery was $54.55 \%(12 / 22)$. There was significant difference between the two groups (c2 $=5.215, P=0.022<0.05)($ Table 2 and table 3$)$.

Table 1 general charactieristics of two groups

\begin{tabular}{|c|c|c|c|c|c|c|c|}
\hline \multirow[t]{2}{*}{ Groups } & \multirow[t]{2}{*}{ Eyes } & \multicolumn{2}{|c|}{ Gender囚eyes $\rrbracket$} & \multicolumn{2}{|c|}{$\begin{array}{l}\text { Eye type } \\
\text { \eyes } \\
end{array}$} & \multirow{2}{*}{$\begin{array}{l}\text { Ageđyears } \rrbracket \\
\square M e a n \pm S D \square\end{array}$} & \multirow{2}{*}{ 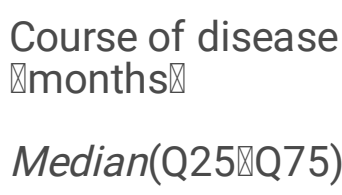 } \\
\hline & & Male & Female & Left & Right & & \\
\hline \multirow[t]{2}{*}{ Group A } & 26 & 1 & 25 & 15 & 11 & $55.42 \pm 12.22$ & 24.0 \\
\hline & & & & & & & $(10.5 \varangle 42.0)$ \\
\hline \multirow[t]{2}{*}{ Group B } & 22 & 3 & 19 & 10 & 12 & $55.82 \pm 9.35$ & 12.0 \\
\hline & & & & & & & $(6.0 \rrbracket 24.0)$ \\
\hline $\begin{array}{l}\text { Inspection } \\
\text { value }\end{array}$ & & \multicolumn{2}{|c|}{$c^{2}=1.495$} & \multicolumn{2}{|c|}{$c^{2}=0.715$} & $t=-0.124$ & $Z=-1.022$ \\
\hline$P$ value & & \multicolumn{2}{|l|}{0.320} & \multicolumn{2}{|c|}{0.563} & 0.902 & 0.307 \\
\hline
\end{tabular}

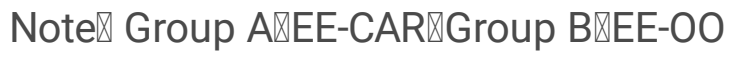

Table 2 The curative effect of the two groups at 6 months postoperatively 


\begin{tabular}{|c|c|c|c|}
\hline Groups & Eyes & Success》eyes, \%邓 & Fail囚eyes, \%区 \\
\hline Group A & 26 & $22 \rrbracket 84.62 \% \rrbracket$ & $4 \rrbracket 15.38 \% \rrbracket$ \\
\hline Group B & 22 & $12 \rrbracket 54.55 \% \rrbracket$ & $10 \rrbracket 45.45 \% \rrbracket$ \\
\hline$c^{2}$ value & 5.215 & & \\
\hline$P$ value & 0.022 & & \\
\hline
\end{tabular}

Note『 Group A囚EE-CAR囚Group B囚EE-OO

Table 3 Cause analysis of ostium atresia postoperative

\begin{tabular}{|c|c|c|c|}
\hline Groups & $\begin{array}{l}\text { Granulation Tissue } \\
\text { formation囚eyes } \rrbracket\end{array}$ & $\begin{array}{l}\text { Scar } \\
\text { hyperplasia } \\
\text { 囚eyes } \rrbracket\end{array}$ & 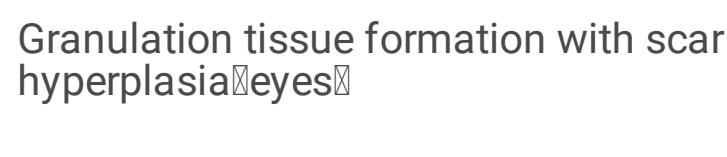 \\
\hline $\begin{array}{l}\text { Group } \\
\text { A }\end{array}$ & 1 & 2 & 1 \\
\hline $\begin{array}{l}\text { Group } \\
\text { B }\end{array}$ & 3 & 4 & 3 \\
\hline
\end{tabular}

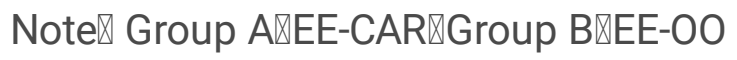

\section{Discussion}

EE-CAR, as the name suggests, the opening of the common canaliculus needs to be completely opened and directly exposed to the nasal cavity. But, for patients without the structure of the common canaliculus, the opening of the upper and lower lacrimal canaliculi in the lacrimal sac area needs to be exposed [19]. Because the lacrimal sac is a wedge-shaped membranous sac, the upper end is the blind end, which is wide and the lower end is narrow, the opening of the common canaliculus or lacrimal canaliculi in the lacrimal sac area is directly exposed to the nasal cavity. As far as the EE-CAR is concerned, its incision is the wide sac near the blind end of the lacrimal sac, which reduces the compression and restriction of the lacrimal sac mucosal flap on the spatial structure of the ostium [2021].

In EE-DCR surgery, nasal mucosa and lacrimal sac mucosa needs to be cut and anastomosed, and the ostium finally presents a closed state, that is, failure. For the patients who have undergone DCR and finally closed the ostium, on the one hand, the mucosa of the surgery area is different from that of normal patients who have not been operated, on the other hand, such patients can be classified into the category of recurrent constitution. As we all know, the formation of a perfect ostium requires the joint action of mucosa and bone $[11,18]$. Studies have pointed out that when the bone pore is too small or the bone window is low during EE-DCR, the Rosenmüller valve is not exposed, resulting in insufficient ostium space. At this time, the produced ostium stoma is very prone to atresia [22-23]. In the face of patients with 
recurrent lacrimal duct obstruction, we need to consider whether the patient's previous ostium needs to be improved and special treatment. Although such patients may be more prone to tissue adhesion and hyperplasia than ordinary people, if sufficient space and external conditions can be given to the ostium during reoperation, the recurrence rate will be reduced. The full opening of lacrimal sac cavity is the key to the success of reoperation in patients with atresia of rhinostomy ostium.

The EE-CAR in this study can be understood as a high-position EE-DCR, which not only exposed the common canaliculus, but also exposed the Rosenmüller valve. Because the upper part of the lacrimal sac is fully exposed, the "lacrimal sac pump" may suffer some damage, but this range does not affect the lacrimal canaliculi, so the lacrimal canaliculi pump and lacrimal canaliculi siphon will not be affected. At the same time, tear drainage functions such as gravity and air convection can still have a certain impact on tear excretion. Therefore, the EE-CAR will not have a great impact on the overall lacrimal duct pump function [22,24]. On the contrary, due to the expansion and high opening of the bone window, it gives sufficient growth and healing space for the ostium, which can indirectly reduce the extrusion and adhesion between the mucosa at the ostium, and reduce the granulation tissue stimulated by tissue adhesion $[4,25]$. On the other hand, in this study, the scar tissue at the original ostium was fully removed during the EE-CAR. The newly made mucosa at the ostium was mostly taken from the tissue at the top of the lacrimal sac. There was no obsolete scar tissue in the mucosa, which greatly reduced the risk of abnormal hyperplasia or poor healing of the newly made ostium flap stimulated by the obsolete scar tissue. In group B, the original ostium was cut. Although some scar tissue was also removed, the completed ostium was surrounded by the residual obsolete scar tissue at the original ostium. Although the short-term curative effect was acceptable, after a period of tissue repair and healing, the mucosa at this site will proliferate a physiological structure different from the normal mucosa, it's very easy to make the ostium locked again. Moreover, directly reopening the ostium at the original ostium did't correct the possible deficiencies in the shape or spatial position of the original ostium (Fig. 2D). If the bone window is not open enough or the spatial position is too low, it will still restrict the growth of the ostium again, greatly increasing the risk of recurrence.

\section{Conclusion}

In summary, the EE-CAR in the treatment of patients with small lacrimal sac remnant after EE-DCR due to ostium atresia has a really curative effect. Compared with simple ostium incision, it can significantly improve the success rate of reoperation in patients with EE-DCR failure, with significant curative effect, and has a certain value of clinical application.

A

\section{Declarations}

\section{Conflict of interest}

The authors declare that they have no conflict of interest. 


\section{Ethical approval}

All procedures in studies involving human participants were performed in accordance with the ethical standards of the institution and with the 1964 Helsinki Declaration and its later amendments or comparable ethical standards.

\section{Informed consent}

Informed consent was obtained from all individual participants included in the study.

\section{Ethics approval and consent to participate}

This study followed the tenets of the Declaration of Helisinki and was approved by the ethics committee of Hankou Eye Hospital of Wuhan Aier (approval No.:HKAIER2018IRB-002-01).

\section{Consent for publication}

All the patients included in this study gave written consent by their guardians for their personal or clinical details along with any identifying images to be published in this study.

\section{Availability of Data and Materials (ADM)}

All data generated or analyzed during this study are included in this published article and its supplementary information files.

\section{Competing interests}

The authors declare that they have no competing interests.

\section{Funding}

No funding.

\section{Authors' contributions}

Sha Li coordinated the date collection, analyzed and interpreted the data, and drafted the manuscript. Yong Zhang performed the experiments. All authors discussed the results and contributed to the final manuscript. All authors have read and approved the final manuscript.

\section{Acknowledgements}

The authors thank Dr. Wencan Wu and Dr. Yunhai Tu for their useful discussion on the relevant topics of this study.

\section{References}


[1] Yanık Ö,Hoşal B,Tekeli A,et al. Viral nucleic acid analysis with PCR in lacrimal tissue and nasal swab samples of primary acquired nasolacrimal duct obstruction cases. Eur J Ophthalmol. 2021;31(1):138143. doi:10.1177/1120672119882331

[2] Qin Q,Li B,Ming J, et al. Clinical efficacy comparison of low-temperature plasma radiofrequency ablation and Nd:YAG laser in treating recurrent acquired nasolacrimal duct obstruction. Lasers Med Sci. 2020;35(9):1937-1944.doi: 10.1007/s10103-020-02982-8

[3] Yang D. Influence of different methods of silicone tube intubation on clinical effects and safety of patients with chronic dacryocystitis. Lin Chung Er Bi Yan Hou Tou Jing Wai Ke Za Zhi. 2020;34(4):340342.doi: 10.13201/j.issn.2096-7993.2020.04.013

[4] Yu B,Qian Z,Han X,et al. Endoscopic Endonasal Dacryocystorhinostomy With a Novel Lacrimal Ostium Stent in Chronic Dacryocystitis Cases With Small Lacrimal Sac. J Craniofac Surg. 2020;31(5):1348-1352. doi:10.1097/SCS.0000000000006359

[5] Kshirsagar RS, Vu PQ, Liang J. Endoscopic versus external dacryocystorhinostomy: temporal and regional trends in the United States Medicare population. Orbit. 2019;38(6):453-460. doi:10.1080/01676830.2019.1572767

[6] Kaçaniku G, Ajazaj V, Shabani A, et al. Assessing the usefulness of different silicone tubes in external dacryocystorhinostomy. Med Arch. 2018;72(6):414-417. doi:10.5455/medarh.2018.72.414-417

[7] Eyigor H, Cetinkaya EA, Coban DT, et al.Sinonasal effects of external dacryocystorhinostomy. J Laryngol Otol. 2021;undefined(undefined):1-4. doi:10.1017/S002221512100181X

[8] Kim S,Kim CH,Park J, et al. Salvage of impending rhinostomy failure after dacryocystorhinostomy with office-based microdebrider treatment. Graefes Arch Clin Exp Ophthalmol. 2021;undefined: undefined. doi:10.1007/s00417-021-05421-8

[9] Trimarchi M, Giordano Resti A, Vinciguerra A, et al. Dacryocystorhinostomy: evolution of endoscopic techniques after 498 cases. Eur J Ophthalmol. 2020;30(5):998-1003. doi:10.1177/1120672119854582

[10] Jawad A, Kausar A, Iftikhar S, et al. Results of endoscopic endonasal dacryocystorhinostomy: a prospective cohort study. J Pak Med Assoc. 2021;71(5):1420-1423. doi:10.47391/JPMA.187

[11]At'kova EL,Krakhovetskiy NN,Zhukov OV. Endonasal balloon dacryoplasty in partial and complete obstruction of dacryocystorhinostomy ostium. Vestn Oftalmol. 2021;137(1):13-20.

doi:10.17116/oftalma202113701113

[12] De Castro DK,Santiago YM,Cunningham $M$, et al. A modified lacrimal sac implant for high-risk dacryocystorhinostomy. Ophthalmic Plast Reconstr Surg. 2013;29(5):367-72.

doi:10.1097/IOP.0b013e31829a72d4 
[13] Anijeet D,Dolan L,Macewen CJ. Endonasal versus external dacryocystorhinostomy for nasolacrimal duct obstruction. Cochrane Database Syst Rev. 2011;19(1):CD007097

[14] At'kova EL, Krakhovetskiy NN, Zhukov OV. Transcanalicular balloon dacryoplasty for the treatment of post-dacryocystorhinostomy recurrent stenoses]. Vestn Oftalmol. 2020;136(null):163-169.

doi:10.17116/oftalma2020136052163

[15] Qin Q, Li B, Ming J, et al.Clinical efficacy comparison of low-temperature plasma radiofrequency ablation and Nd:YAG laser in treating recurrent acquired nasolacrimal duct obstruction. Lasers Med Sci. 2020;35(9):1937-1944. doi:10.1007/s10103-020-02982-8

[16] Du J, Zhong B, Xian J, et al. Effect of revision dacryocystorhinostomy under nasal endoscopy on recrudescent dacryocystitis. Int J Clin Exp Pathol. 2017;10(12):11717-11722.

[17] Trott S,Colgrove N,Westgate P,et al. Systematic review of endoscopic-assisted surgical management for congenital nasolacrimal duct obstruction. Int J Pediatr Otorhinolaryngol.

2020;139(undefined):110448. doi: 10.1016/j.ijporl.2020.110448

[18]Bielecki P,Gindzienska-Sieskiewicz E,Reszeć J,et al. Expression of LIGHT/TNFSF14 and Its Receptors, HVEM and LT $\beta R$, correlates with the severity of fibrosis in lacrimal sacs from patients with lacrimal duct obstruction. Ophthalmol Ther. 2021;10(1):63-74. doi: 10.1007/s40123-020-00320-3

[19] Pan ZQ, Liu JJ, Jia XK, et al.Endoscopic transnasal canaliculorhinostomy for refractory common canalicular obstruction with an unidentifiable lacrimal sac. Int J Ophthalmol. 2020;13(8):1238-1243. doi:10.18240/ijo.2020.08.09

[20]Pagella F,Pusateri A,Matti E,et al. An easy method for intraoperative confirmation of lacrimal sac patency in endoscopic dacryocystorhinostomy. Eur J Ophthalmol. 2017;27(3):379-381.

doi:10.5301/ejo.5000917

[21]Ali MJ. Valve of Rosenmüller: Endoscopic Real-Time Analysis of Two Subtypes and Potential Functional Implications. Ophthalmic Plast Reconstr Surg. 2020;36(1):94-97.

doi:10.1097/IOP.0000000000001483

[22] Sun $Y$, Wang $H$, Wang $Y$, et al. Endonasal endoscopic treatment of recurrent dacryocystitis. Cell Biochem Biophys. 2013;67(3):1441-4. doi:10.1007/s12013-013-9684-7

[23]Callejas CA,Tewfik MA,Wormald PJ. Powered endoscopic dacryocystorhinostomy with selective stenting. Laryngoscope. 2010;120(7):1449-1452. doi: 10.1002/lary.20916

[24] Mimura M,Ueki $\mathrm{M}, \mathrm{Oku} \mathrm{H}$,et al. Evaluation of granulation tissue formation in lacrimal duct post silicone intubation and its successful management by injection of prednisolone acetate ointment into the lacrimal duct. Jpn J Ophthalmol. 2016;60(4):280-285. doi: 10.1007/s10384-016-0446-0 
[25]Struck HG,Heichel J. Lacrimal Stenosis after Chemical and Thermal Ocular Burns. Klin Monbl Augenheilkd. 2019;236(9):1103-1106. doi: 10.1055/a-0808-4909

\section{Figures}
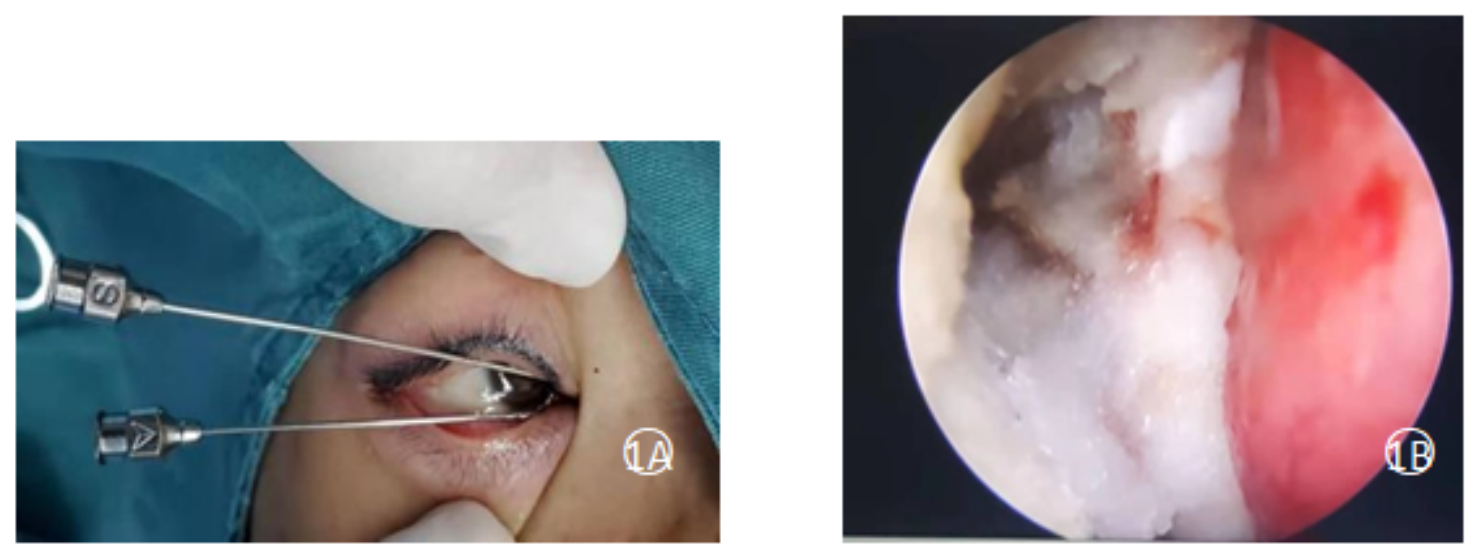

Figure 1

EE-CAR囚right eye $\rrbracket$

$\mathrm{A} \otimes T$ The probe enters the lacrimal sac area horizontally from the upper and lower lacrimal punctum $\mathbb{B} \square$ Avitene Microfibrillar Collagen Hemostat Flour was used to fill the ostium and nasal cavity 

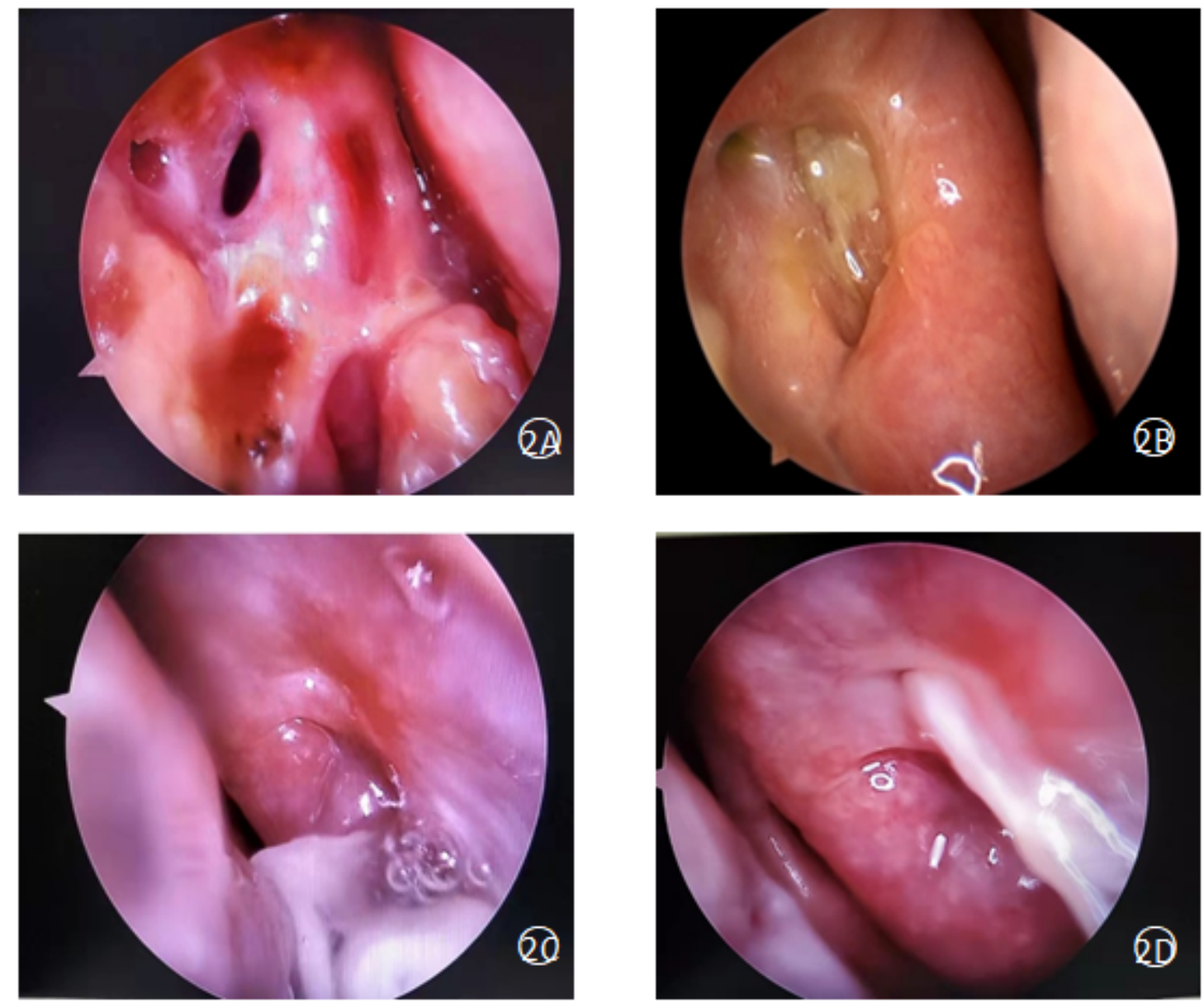

Figure 2

Various types of ostium postoperatively

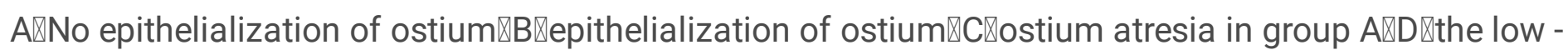
position ostium was closed by purulent secretion in group $B$

\section{Supplementary Files}

This is a list of supplementary files associated with this preprint. Click to download.

- rawdata.xlsx 